It can be blocked by atropine, suggesting that it is brought about by the vagus, probably through the action of the latter on bronchial smooth muscle.

I would like to thank Dr. J. C. Batten for his advice and encouragement, and Miss F. A. Boother for her frequent technical help.

This study was supported by a research grant from the Board of Governors, St. George's Hospital, London S.W.1.
REFERENCES

Briscoe, W. A., and DuBois, A. B. (1958). 7. clin. Invest., 37, 1279. DuBois, A. B., Botelho, S. Y., and Comroe, J. H. (1956). Ibid., 35, 327 Hyatt, R. E., and Wilcox, R.' E. (1961). F. appl. Physiol., 16, 326 McDermott, M., and Collins, M. M. (1965). Thorax, 20, 562 . Nadel, J. A., and Comroe, J. H., jun. (1961). \%. appl. Physiol. 16,713 .

Salem, H., Tamplin, B., and Tokiwa, Y. (1965). Ibid., 20, 164. - and Widdicombe, J. G.' (1962). Ibid., 17, 861.

Pelzer, A. M., and Thomson, M. L. (1966). Ibid., 21, 469.

Widdicombe, J. G., Kent, D. C., and Nadei, J. A. (1962). Ibid., 17, 613 Zamel, N., Youssef, H. H., and Prime, F. J. (1963). Lancet, $1,1237$.

\title{
Is the Woulfe Bottle an Efficient Humidifier for Oxygen?
}

\author{
BERNARD J. FREEDMAN,* M.B., B.S., M.R.C.P.
}

Brit. med. 7., 1967, 3, 277-279

Oxygen from cylinders is dry. The need for adequate humidity of inhaled gases in oxygen therapy is generally recognized. There is, however, no unanimity regarding the desirable level of humidity, nor regarding the best means of achieving it. Bubbling oxygen through water in a Woulfe bottle has been the most widely used method of humidifying oxygen since the early days of oxygen therapy. This method has been the object of adverse criticism. It has been alleged that it "does not result in adequate humidification" and that "this method should be abandoned" (Brit. med. F., 1964). Cadman (1961) was of similar opinion. The Woulfe bottle is a widely used apparatus for this purpose, and in many hospitals it is the only one. Before urging the widespread abandonment of a cheap, simple, and easily replaceable apparatus in favour of something complex and expensive, or of giving it up altogether, it seemed desirable to test the efficiency of the Woulfe bottle as a humidifier, since no record could be found of this having been previously done.

There are three questions to answer. What level of humidification does this method achieve within the range of working conditions likely to be encountered ? What level of humidification is desirable? Does this method meet chinical requirements? Experiments are described which give an answer to the first question, and an attempt is made to answer the second and third in the discussion which follows.

\section{Material and Methods}

Conventional bedside apparatus was used. Oxygen from a cylinder was bubbled through water in a Woulfe bottle and conveyed thence by $1.5 \mathrm{~m}$. ( $4 \mathrm{ft}$. 9 in.) of rubber tubing to a hair hygrometer which occupied the position of a face-mask. Oxygen flow-rates were measured with a bobbin flow-meter calibrated against a Parkinson-Cowan gas-meter. The Woulfe bottle measured $14 \mathrm{~cm}$. high and $5.8 \mathrm{~cm}$. internal diameter, and it was filled to a depth of $4.5 \mathrm{~cm}$. (about $160 \mathrm{ml}$.) with tapwater, the inlet tube reaching to $0.5 \mathrm{~cm}$. above the floor of the bottle. The tube conveying oxygen from the bottle was connected to an opening in one end of a transparent polyvinyl chloride bag. The hygrometer lay within the bag. It fitted fairly snugly so as to ensure adequate entry of humidified oxygen into its casing (Fig. 1). Oxygen left the bag through tubes inserted into the two distal corners. This prevented retrograde entry of ambient air. The hair hygrometer was calibrated against a wet-and-dry bulb whirling hygrometer.
Dry oxygen was passed through water in the Woulfe bottle at a constant rate. At intervals of two minutes or less the following were measured: (1) relative humidity in the bag, and (2) temperature of the water, of the gas in the bag reaching the hygrometer, and of the ambient air. Gas flow continued until stable readings were obtained. Duplicate experiments were

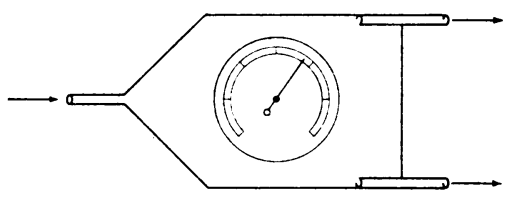

Fig. 1.-Humidified oxygen is passed through the plastic bag containing the hygrometer.

performed at flow-rates of 3,5, and 8 litres per minute in cool, temperate, and hot environments. The hot environment was in the hospital basement alongside the steam-pipes, the temperate was in the laboratory, and the cool was on a ward balcony. Day-to-day variations in weather conditions and in boiler temperatures rendered it impossible to achieve identical ambient temperatures in the experiments carried out within each of the three temperature ranges. Ambient temperatures were as follows :

$\begin{array}{lllllll}\text { Cool } & \ldots & \ldots & 11.0-13.4^{\circ} & \text { C. }\left(51.8-56.1^{\circ}\right. & \text { F. }) \\ \text { Temperate } & \ldots & 18.5-19.8^{\circ} & \text { C. }\left(65.3-67.6^{\circ}\right. & \text { F. }) \\ \text { Hot } \quad \ldots & \ldots & 27.6-31.6^{\circ} & \text { C. }\left(81.7-88.9^{\circ}\right. & \text { F. })\end{array}$

\section{Results}

After the oxygen was turned on, the humidity rose rapidly. Progressive cooling of the water then led to a corresponding fall in humidity. Eventually the water temperature and the relative humidity were steady. A high flow-rate and a high ambient temperature were associated with much cooling of the water (Table I), and a big drop in final humidity. For example, at $8 \mathrm{1} . / \mathrm{min}$. and $31.5^{\circ} \mathrm{C}$. $\left(88.7^{\circ} \mathrm{F}\right.$.), the water temperature fell as much as $11.6^{\circ} \mathrm{C}$. $\left(20^{\circ} \mathrm{F}\right.$.).

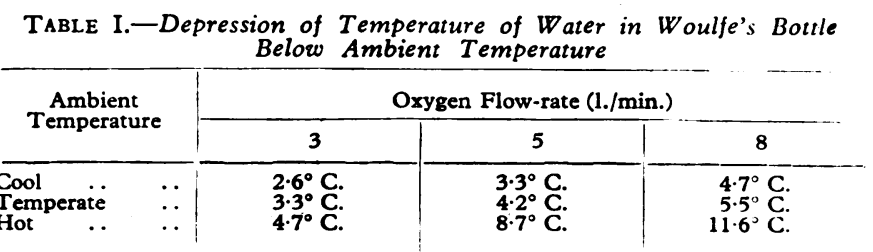


Despite the cooling of oxygen that must have occurred, it was always rewarmed to within a degree of ambient temperature in the course of its passage along the tube to the hygrometer. The results shown in Table II are the levels of humidity which were eventually reached after the initial rise and fall when conditions were stable, and are the means of closely agreeing duplicates.

TABLE II.-Humidity of Oxygen After Bubbling Through Water in a Woulfe Bottle at Three Flow-rates and Three Ambient Temperatures

\begin{tabular}{|c|c|c|c|c|}
\hline & \multicolumn{3}{|c|}{$\begin{array}{l}\text { Oxygen Flow-rate } \\
\text { (litres/min.) }\end{array}$} \\
\hline & & 3 & 5 & 8 \\
\hline $\begin{array}{l}\text { A. Water-vapour con- } \\
\text { centration (grammes } \\
\text { water per cubic metre } \\
\text { oxygen) }\end{array}$ & $\begin{array}{l}\text { Cool } . . \\
\text { Temperate } \\
\text { Hot } \quad . .\end{array}$ & $\begin{array}{r}8 \cdot 34 \\
13.40 \\
22.74\end{array}$ & $\begin{array}{r}8 \cdot 75 \\
13 \cdot 03 \\
22 \cdot 57\end{array}$ & $\begin{array}{r}7.95 \\
11.50 \\
19 \cdot 42\end{array}$ \\
\hline $\begin{array}{l}\text { B. Relative humidity } \\
(\%) \ldots \quad \ldots\end{array}$ & $\begin{array}{l}\text { Cool } \\
\text { Temperate } \\
\text { Hot }\end{array}$ & $\begin{array}{l}70 \\
79 \\
81 \cdot 5\end{array}$ & $\begin{array}{l}70 \cdot 5 \\
80 \\
68\end{array}$ & $\begin{array}{l}75 \\
70 \\
60\end{array}$ \\
\hline $\begin{array}{l}\text { C. Evaporation rate } \\
\text { (mg. water evapor- } \\
\text { ated per minute) }\end{array}$ & $\begin{array}{l}\text { Cool } \\
\text { Temperate } \\
\text { Hot }\end{array}$ & $\begin{array}{l}25 \cdot 0 \\
40 \cdot 2 \\
68 \cdot 2\end{array}$ & $\begin{array}{r}43 \cdot 7 \\
65 \cdot 2 \\
112 \cdot 8\end{array}$ & $\begin{array}{r}63.6 \\
92.0 \\
155.4\end{array}$ \\
\hline
\end{tabular}

Water-vapour concentrations achieved in these experiments (Table II A) ranged from $7.95 \mathrm{~g} . / \mathrm{cu}$. m. (at low ambient temperature and high flow-rate) to $22.74 \mathrm{~g} . / \mathrm{cu}$. m. (at high ambient and low flow-rate). A rise in temperature yielded a striking increase in water-vapour content. A rise in flow-rate made little difference. The figures were obtained by calculation from the relative humidity (Table II B), the temperature, and values for water-vapour concentrations in saturated air at various temperatures (Hygrometric Table, 1940).

Table II $\mathrm{B}$ shows relative humidities, measured as described in the experiments, which ranged from 60 to $81.5 \%$.

Table II C shows weight of water vaporized per minute, which ranged from 25 to $155 \mathrm{mg}$., the quantity varying as temperature and flow-rate. The figures were obtained by calculation from concentrations (Table II A) and flow-rates.

The effectiveness of humidification must be judged by the water-vapour concentration (expressed here in g./cu. m.) and not by relative humidity or the amount of water vaporized in one minute. Table II A therefore shows the essential results in this connexion. It cannot be too strongly emphasized that relative humidity readings are of limited value and must lead to fallacious conclusions unless taken in conjunction with temperature and expressed as water-vapour concentration. Air or oxygen which is saturated with water vapour at body temperature contains $44 \mathrm{~g}$. of water per cubic metre. The drying power of inspired gases is proportional to the amount by which their water content falls short of this amount. Fig. 2 shows the water-vapour concentration at various relative humidities and temperatures, and has been drawn from values calculated from the Hygrometric Table (1940). Comparison of Table II A and II B shows some of the differences between water-vapour concentration and relative humidity in identical circumstances, and demonstrates the fallacy of accepting the latter in preference to the former. For example, at a flow-rate of $81 . / \mathrm{min}$. the relative humidity is $75 \%$ in a cool environment and $60 \%$ in a hot one (Table II B), yet the corresponding water-vapour concentrations are 7.95 and $19.42 \mathrm{~g} . / \mathrm{cu}$. m. respectively (Table II A). The hot environment thus yields a higher water-vapour concentration, despite the lower relative humidity, than the cool one. Fig. 3 shows water-vapour concentrations occurring during the course of the experiments, strikingly showing the effect of ambient temperature.

\section{Discussion}

What level of humidification is desirable? In extreme atmospheric conditions, as in Himalayan mountaineering, there is evidence that during a stay of several weeks under conditions involving strenuous physical activity there is some liability to bronchitis (Pugh and Ward, 1953; Ward, 1953). In these circumstances the cold air at low pressure has an exceedingly low water-vapour content. However, in the range of atmospheric conditions likely to be encountered in clinical practice,

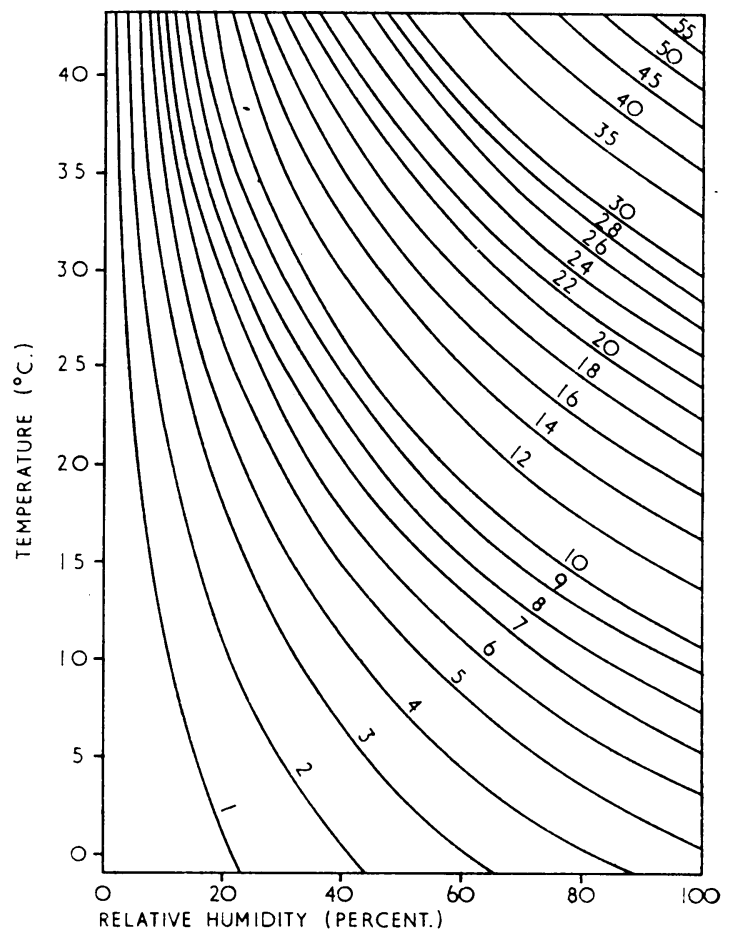

FIG. 2.-Given relative humidity and temperature, the absolute humidity, or water-vapour concentration in grammes per cubic metre of gas, can be derived from these curves. Each curve represents the number of grammes per cubic metre.

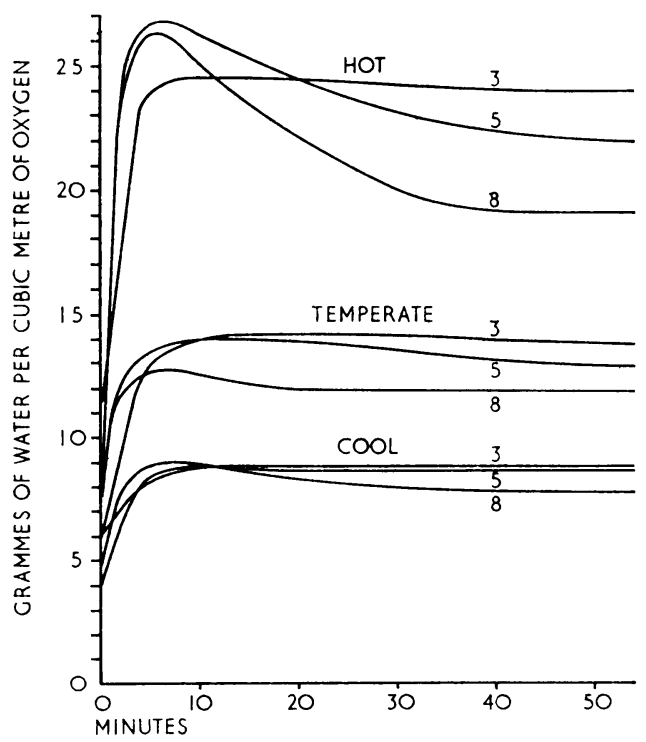

Fig. 3.-Examples of the sequence of changes that occur in absolute humidity (grammes of water per cubic metre) in oxygen when it is bubbled through water in a Woulfe bottle at three flow-rates ( 3,5 , and 8 litres per minute) and at three ambient temperatures.

air inhaled through the nose is warmed to within a degree or two of body temperature and saturated with water vapour. Perwitzschky (1927) showed that air at $25^{\circ}$ C. $\left(77^{\circ}\right.$ F.) and relative humidity $24 \%$ inhaled through the nose acquires a relative humidity of $99 \%$ at $35-36^{\circ} \mathrm{C}$. $\left(95-97^{\circ} \mathrm{F}\right.$.) by the time it reaches the trachea. Even with mouth-breathing it acquires 
a relative humidity of $93 \%$ at a temperature of $34.5^{\circ} \mathrm{C}$. $\left(94^{\circ}\right.$ F.). At the ambient temperature and relative humidity of his experiment air contains $5.52 \mathrm{~g}$. of water vapour per cubic metre.

In the experiments described here the water-vapour content of the humidified oxygen was in the range of 7.95 to $22.74 \mathrm{~g}$./ cu. m. This is above the amount which Perwitzschky has shown will rise to almost saturation level at body temperature in the trachea. His experiments were carried out on healthy subjects and lasted five minutes each. It is possible that prolonged mouth-breathing would have led eventually to a lower relative humidity in the trachea.

There seem to have been no comparable experiments in patients. One is therefore obliged to consider the varying circumstances that affect patients, and to speculate on their influence on humidity in the airways and the state of the bronchi. The purpose of humidification of oxygen for inhalation is the reduction of its capacity to dry the mucosa of the airways and of the mucus lying thereon. What constitutes a desirable level of humidification depends on factors that vary from patient to patient. A high level of humidity is required in the following circumstances: sticky mucus, a weak cough, a partially obstructed nose, prolonged mouth-breathing, a tracheostomy, and the use of masks involving admixture with ambient air when the latter is excessively dry.

My experience of many cases of acute chest infection over a number of years suggests that cases of moderate severity receive adequate humidification by the Woulfe bottle method. The indications of inadequate humidification are a dry mouth, strings of sticky mucus in the fauces, a rattly but unproductive cough with an adequately expulsive blast, or the expectoration of small amounts of very tenacious mucus with undue effort. These signs are especially likely to occur in gravely ill patients whose infections are complicated by emphysema or asthma, and in whom the maximal expiratory flow-rate and expulsive blast are much reduced. Patients with acute chest infections who have undergone tracheostomy are in similar plight. These patients require inspired gases which are saturated at body temperature.

\section{Summary}

The method of humidifying oxygen by bubbling it through water in a Woulfe bottle has been criticized. This method was tested by bubbling oxygen at three flow-rates $(3,5$, and $81 . /$ min.) and at three ambient temperatures (approximately $12^{\circ}$, $20^{\circ}$, and $32^{\circ}$ C.). The relative humidities ranged from 60 to $82 \%$, and water-vapour concentrations from 7.95 to $22.74 \mathrm{~g} . /$ cu. m. During the first few minutes of bubbling, before appreciable cooling had occurred in the water in the Woulfe bottle, the humidities were still higher. It is thought that humidification of oxygen by this method is adequate for the treatment of most chest infections and for non-respiratory disorders requiring oxygen.

Attention is again drawn to the fallacy of accepting relative humidity alone as a measure of the humidification of gases for inhalation. The need to use measurements of water-vapour concentrations for this purpose is emphasized.

A family of curves has been drawn to facilitate calculation of water-vapour concentration when the relative humidity and temperature are known.

I wish to thank Mr. C. Hinkel, of the Meteorological Office, for advice, and the South-east Metropolitan Regional Hospital Board and King's College Hospital for the grant of equipment and technical assistance.

Brit. med. F., 1964, 2, 1580.

REFERENCES

Cadman, E. F. B. (1961). Brit. med. 7., 1, 591

Hygrometric Tables, Meteorological Office, MO.265, 4th ed., 1940 (reprinted 1956). Appendix IIIB, p. 44.

Perwitzschky, R. (1927). Arch. Ohr.-, Nas.-, u. Kehlk.-Heilk., 117, 1.

Pugh, J., and Ward, M. (1953) The Ascent of Everest, by J. Hunt p. 278. London.

Ward, M. (1953). "The Medical Aspects of Mountaineering." Report on R.C.P. meeting, p. 14.

\title{
Heparin as an Analgesic in Myocardial Infarction: A Double-blind Trial
}

\author{
C. J. BULPITT,* M.B., M.R.C.P.
}

Brit. med. F., 1967, 3, 279-281

Nichol et al. (1959) reported that heparin usually relieves anginal pain, but no controls were employed. This impression has been repeated (British Medical fournal, 1966) but never proved. Heparin does not increase forearm blood flow (Lambert, 1958) and there is no evidence of a vasodilator effect. It was decided, therefore, to perform a double-blind study on the effects of intravenous heparin on myocardial pain, blood pressure, pulse rate, and electrocardiographic tracings. Twenty-eight patients with " myocardial infarction" took part in the trial.

\section{Method}

The patients had been admitted to a general medical ward, usually in the Medway Hospital. To enter the trial a patient had to satisfy the following criteria: he should have cardiac ischaemic pain but not show more than slight distress; he should not have received an anticoagulant within the preceding * Medical Registrar, Medway Hospital, Gillingham, Kent. Present
address: Whipps Cross Hospital, London. few days, nor an opiate or drug of similar analgesic potency within the preceding six hours.

When the patient was first seen by a doctor a quick assessment was made. If the patient was not unduly distressed, and it was thought that no analgesic therapy would be required for 30 minutes, he was requested to enter the trial. He was told that he would receive an intravenous injection of a wellknown drug, to discover whether or not it would relieve his pain. One patient who showed distress during this trial was given morphine and withdrawn.

Each patient verbally answered the first of three questionaries. An intravenous injection of either $2 \mathrm{ml}$. of normal saline or $2 \mathrm{ml}$. of a solution containing 10,000 units of heparin was then given. The solutions, which were identical in appearance, were prepared in numbered phials and used in numerical order. The code was held by the pharmacist; who had randomly allocated the solutions.

The blood pressure and pulse rate were recorded, and nine patients had an electrocardiogram taken before and after the 